\title{
Systematic review: treatment pattern and clinical effectiveness and safety of pharmaceutical therapies for Crohn's disease in Europe
}

This article was published in the following Dove Press journal:

Clinical and Experimental Gastroenterology

5 October 2016

Number of times this article has been viewed

\author{
Filippo Lelli' \\ Solomon Nuhoho \\ Xin Ying Lee ${ }^{3}$ \\ Weiwei $X u^{4}$
}

'EMEA Hemar, Janssen, Milan, Italy; ${ }^{2}$ Health Economics, Market Access and Reimbursement, Johnson \& Johnson Middle East FZ LLC, Dubai, United Arab Emirates; ${ }^{3}$ EMEA Hemar, Janssen, Birkerød, Denmark; ${ }^{4}$ Pharmerit International, Rotterdam, the Netherlands
Correspondence: Weiwei $\mathrm{Xu}$

Pharmerit International, Marten Meesweg 107, 3068 AV Rotterdam, the Netherlands

Tel +3 I 884400 I I7 / +3 I 653380569

Email wxu@pharmerit.com
Background: Although many clinical trials have been conducted in treatments of Crohn's disease (CD), whether the trial results were representative of daily practice needs to be supported by studies conducted in real-world settings.

Aim: This study aims to identify how CD is treated and what are the clinical effectiveness and safety of the pharmaceutical therapies of CD in real-world settings.

Methods: A systematic literature review was conducted based on Medline ${ }^{\circledR}$, Embase ${ }^{\circledR}$, and Cochrane. All publications were assessed for title/abstract and full-text according to a predefined study protocol. Data were extracted and reported.

Results: A total of 1,998 publications were identified. Fifty studies including six publications reporting treatment pattern and 44 studies reporting clinical effectiveness and safety of pharmaceutical therapies in CD management in Europe were included. 5-Aminosalicylic acid and corticosteroids were reported to be used among 14\%-74\% of CD patients. Immunomodulators were used by $14 \%-25 \%$ and $29 \%-31 \%$ of CD patients as an initial and follow-up treatment, respectively. Biological therapies were used by $25 \%-33 \%$ of $\mathrm{CD}$ patients. A trend toward an increasing use of immunomodulators and biological therapies in Europe has been reported in recent years. Approximately $50 \%$ of patients achieved remission on immunomodulator or biologic treatment, although a relapse rate of up to $23 \%$ has been reported.

Conclusion: There is a trend of treatment shift to immunomodulators and biologics in CD management. Clinical effectiveness of immunomodulators and biologics has been demonstrated, though with a lack of sustainability of the effectiveness.

Keywords: inflammatory bowel disease, real world evidence, biologics, immunomodulators, dose-escalation

\section{Introduction}

Crohn's disease (CD) is an inflammatory bowel disease (IBD). It causes inflammation of the lining of digestive tract, which can lead to abdominal pain, severe diarrhea, fatigue, weight loss, and malnutrition. It is characterized by the formation of strictures, fistulas, ulcers, and granulomas in the mucosa. It may affect people in early childhood until late adulthood and has a significant impact on patient's quality of life due to an increased prevalence of comorbidities. ${ }^{1}$ Although the gastrointestinal manifestation of CD can primarily affect the terminal ileum and colon, it can also compromise any region from the mouth to the rectum of the affected patients. The clinical manifestations of CD can include diarrhea or bloody diarrhea, malnutrition, abdominal pain, and weight loss. Extraintestinal findings, for instance, arthropathy or skin disorders, can also occur and have a substantial impact on the patient's quality of life. ${ }^{2}$ 
A recent study from Tayside (in Scotland) indicates a prevalence rate of $157 / 100,000$, meaning there are $>115,000$ people in the UK with $\mathrm{CD}$ at the present time. ${ }^{3}$ The causes of CD are widely debated. Smoking, genetic predisposition, and environmental factors are considered as important factors that are likely to play a role. ${ }^{3,4}$

$\mathrm{CD}$ is a progressive disease with long-term damage to intestinal mucosa (if not controlled properly) and recurrent attacks, with acute exacerbations interspersed with periods of remission or less active disease. ${ }^{3}$ Treatment is largely directed at managing flares and inducing/maintaining remission, rather than curing, and active treatment of acute disease (inducing remission) should be distinguished from preventing relapse (maintaining remission). ${ }^{3}$

Management options for CD include nutritional therapy, smoking cessation, drug therapy, and, in severe or chronic active disease, surgery. ${ }^{3}$ The aims of drug treatment are to reduce symptoms and maintain or improve quality of life, while minimizing toxicity related to drugs over both the short and long term. Glucocorticosteroids (ie budesonide) are recommended to be the first-line pharmaceutical for $\mathrm{CD}^{5}$; 5 -aminosalicylate (5-ASA) is recommended by the National Institute for Health and Care Excellence for CD patients in whom glucocorticosteroid treatment is contraindicated. ${ }^{3}$ For moderately active $\mathrm{CD}$, azathioprine (AZA)/6-mercaptopurine (6-MP) or methotrexate in combination with steroids is a treatment option recommended by the European Crohn's and Colitis Organisation (ECCO). Both National Institute for Health and Care Excellence and ECCO recommend biological therapies (eg, anti-tumor necrosis factor (TNF)- $\alpha$ inhibitors and integrin blocker) as an alternative for patients with objective evidence of active disease, who have previously been steroid-refractory, -dependent, or -intolerant. ${ }^{5}$ TNF- $\alpha$ inhibitors (eg infliximab) and/or immunomodulators are used as add-on treatments to glucocorticosteroids in case of severe and active $\mathrm{CD}$ when disease has not responded to conventional therapy or the glucocorticosteroid dose cannot be tapered. ${ }^{3}$ In recent years, there have been other drugs with other mechanisms of action under development, for example, humanized monoclonal antibody that targets interleukin-12 and interleukin-23, janus kinase inhibitors, and integrin inhibitors (eg, vedolizumab). ${ }^{6-9}$

A number of clinical trials have been conducted to evaluate the pharmaceutical treatments in CD. Systematic literature reviews and meta-analyses of these clinical trials were conducted to understand the clinical effectiveness and safety of drugs used in treating CD. A meta-analysis including 12 clinical trials suggested that budesonide was no more effective than placebo for maintenance of remission; however, the overall quality of the evidence supporting this outcome was very low due to sparse data and high risk of bias (single-blind and no allocation concealment). ${ }^{10}$ Another meta-analysis including 27 studies showed that anti-TNF- $\alpha$ antibodies were superior to placebo in inducing remission of luminal CD. Anti-TNF- $\alpha$ antibodies were also superior to placebo in preventing relapse of luminal $\mathrm{CD} .{ }^{11}$ In a systematic literature review including 13 randomized clinical trials with a total of 1,211 participants, it was concluded that immunosuppressive drugs, such as AZA and 6-MP, are no more effective than placebo for inducing remission in $\mathrm{CD} .{ }^{12}$

To the best of our knowledge, there has been no published systematic literature review to investigate how these pharmaceutical therapies are adopted in real-world clinical practice and whether the results from the clinical trials can be generalized to real-world settings.

The objective of this work is to systematically review the treatment pattern of pharmaceutical inventions in $C D$ in real-world clinical practice (in Europe) and the clinical effectiveness and safety of the pharmaceutical therapies that are labeled for the treatment of CD.

\section{Methods}

A systematic literature review was conducted according to the Preferred Reporting Items for Systematic Reviews and MetaAnalyses (PRISMA) guidelines on March 26, 2015, to identify relevant publications regarding current treatment pattern in practice, clinical effectiveness and safety of pharmaceutical therapies in real-life settings, patient preference in $\mathrm{CD}$, and resource utilization/costs of treating $\mathrm{CD}$. Among the aforementioned topics, current treatment pattern in practice and clinical effectiveness/safety of pharmaceutical therapies in real-life settings are the issues of interest for this study. A study protocol was developed to ensure the replicability of this literature review. The study protocol specified databases, limitations, and inclusion and exclusion criteria to be used in selection.

We searched Medline ${ }^{\circledR}$, Embase ${ }^{\circledR}$, and Cochrane (including Health Technology Assessment Database and National Health Service Economic Evaluation Database) to identify articles published from 2000 onwards. Furthermore, conferences including ECCO, conference of United European Gastroenterology, Groupe d'Étude Thérapeutique des Affections Inflammatoires du Tube Digestif, British Society of Gastroenterology, American Gastroenterological Association, and the Digestive disease week were also searched to identify relevant conference abstracts and proceedings in the past 3 years. In addition to the time limitation, the search was limited 
to humans, adult ( $\geq 18$ years), English language, and "article, conference paper, conference proceedings, and review" as document type.

Search terms combined the disease of interest, that is, $\mathrm{CD}$, study type (including all real-world evidence study types suggested by the Scottish Intercollegiate Guidelines Network), ${ }^{13}$ and keywords regarding treatment patterns and clinical effectiveness and safety/tolerability. The search strings used are presented in Table 1.

After removing duplications, titles and abstracts of all results from the databases and conferences were reviewed by one reviewer according to the prespecified inclusion and exclusion criteria (a second reviewer was consulted in case of doubt). Full-text papers were accessed for all publications that were qualified in the title/abstract selection phase according to the same inclusion and exclusion criteria. In order to be able to target recent publications and have a geographic focus of the European countries, a further time limitation from year 2010 and a geographic limitation of Europe, or major European Union countries including UK, Germany, France, Spain, Italy, Sweden, Norway, Denmark, Finland, Belgium, the Netherlands, Luxembourg, and Portugal were used during the full-text selection phase. Publications excluded in the full-text selection phase were reported with reasons in a PRISMA chart.
Data were extracted on current treatment pattern in CD management and clinical effectiveness and safety of pharmaceutical therapies of CD, reported by real-world studies, that is, not in clinical trial settings.

\section{Results}

In this systematic literature review, a total of 1,998 publications were identified by searching Medline, Embase, and Cochrane database. After removing duplicates and screening the titles and abstracts of these 1,998 articles, 755 articles were retrieved and reviewed for full text. Based on the fulltext publications, 705 articles were excluded for reasons according to the study protocol, including ineligible population $(n=125)$; not interventions of interest, for example, surgical intervention and off-label drugs $(n=169)$; not realworld studies $(n=17)$; and irrelevant outcomes $(n=123)$. Furthermore, 166 articles were excluded as they are either published before 2010 or conducted in countries other than those of interest. As the original literature review included also topics of patient preference and resource utilization, studies of these topics $(n=92)$ fell out of the scope of this paper. Thirteen studies were not available for this literature review. The PRISMA chart that describes search and selection procedure is shown in Figure 1.

Table I Search terms (Medline ${ }^{\circledR}$ and Embase ${ }^{\circledR}$ search via ProQuest)

\begin{tabular}{|c|c|c|}
\hline Search & \# & Search terms \\
\hline Indication & $\mathrm{SI}$ & EMB.EXACT(“Crohn disease”) OR MESH.EXACT(“Crohn Disease”) \\
\hline \multirow[t]{9}{*}{ Study type } & S2 & (EMB.EXACT(“case control study”) OR EMB.EXACT(“family study”) OR EMB.EXACT(“'longitudinal study”) OR \\
\hline & & EMB.EXACT(“prospective study") OR EMB.EXACT(“retrospective study”) OR EMB.EXACT(“observational \\
\hline & & study”) OR EMB.EXACT(“cohort analysis”) OR (“medical record review”)) OR (TI,AB(epidemiologic* pre/l \\
\hline & & stud*) OR TI,AB("case control”) OR TI,AB(cohort pre/l stud*) OR TI,AB(“cohort analy*”) OR TI,AB(Follow \\
\hline & & Up pre/l stud*) OR TI,AB(observational pre/l stud*) OR TI,AB(longitudinal) OR TI,AB(retrospective) \\
\hline & & OR TI,AB(“cross sectional”) OR TI,AB(“chart review”) OR TI,AB(“"medical record review”)) OR (MESH. \\
\hline & & EXACT(“"Case-Control Studies”) OR MESH.EXACT(“"Cohort Studies”) OR MESH.EXACT(“Cross-Sectional \\
\hline & & Studies”) OR MESH.EXACT(“Observational Study”) OR MESH.EXACT(“Prospective Studies”) OR MESH. \\
\hline & & EXACT(“Retrospective Studies”) OR MESH.EXACT(“Longitudinal Studies”)) \\
\hline \multirow[t]{3}{*}{ Treatment patterns } & S3 & $\mathrm{TI}, \mathrm{AB}$ (escalation) OR TI,AB(off-label) OR TI,AB(off label) OR (treatment pattern) OR (Standard treatment) \\
\hline & & OR (Standard therapy) OR (Standard of care) OR MESH.EXACT(“Standard of Care”) OR MESH.EXACT. \\
\hline & & EXPLODE(“Standard of Care") OR SoC \\
\hline Comparative & S4 & $\mathrm{Tl}, \mathrm{AB}$ (Activity Index) OR TI,AB(CDAI) OR TI,AB(Mucosal Healing) OR TI,AB(Biomarkers) OR TI,AB(Fecal \\
\hline \multirow[t]{5}{*}{ effectiveness } & & Calprotectin) OR TI,AB(Faecal Calprotectin) OR TI,AB(Deep Remission) OR TI,AB(dose escalation) OR \\
\hline & & $\mathrm{TI}, \mathrm{AB}$ (remission) OR TI,AB(C Reactive Protein) OR TI,AB(CRP) OR (comparative effectiveness) OR (clinical \\
\hline & & effectiveness) OR efficacy OR effect OR TI,AB(effectiveness) OR MESH.EXACT(“Treatment Outcome”) OR \\
\hline & & MESH.EXACT(“Comparative Effectiveness Research”) OR EMB.EXACT(“comparative effectiveness”) OR EMB. \\
\hline & & EXACT(“drug efficacy”) \\
\hline \multirow[t]{4}{*}{ Safety and tolerability } & S5 & AE OR (adverse events) OR (safety) OR (tolerability) OR EMB.EXACT.EXPLODE(“adverse drug reaction”) OR \\
\hline & & MESH.EXACT("Drug-Related Side Effects and Adverse Reactions") OR MESH.EXACT.EXPLODE(“Drug-Related \\
\hline & & Side Effects and Adverse Reactions") OR EMB.EXACT(“adverse drug reaction”) OR MESH.EXACT(“Safety”) OR \\
\hline & & EMB.EXACT(“drug tolerability”) OR EMB.EXACT.EXPLODE(“drug tolerability”) \\
\hline Combined & S7 & SI AND S2 AND (S3 OR S4 OR S5) \\
\hline
\end{tabular}




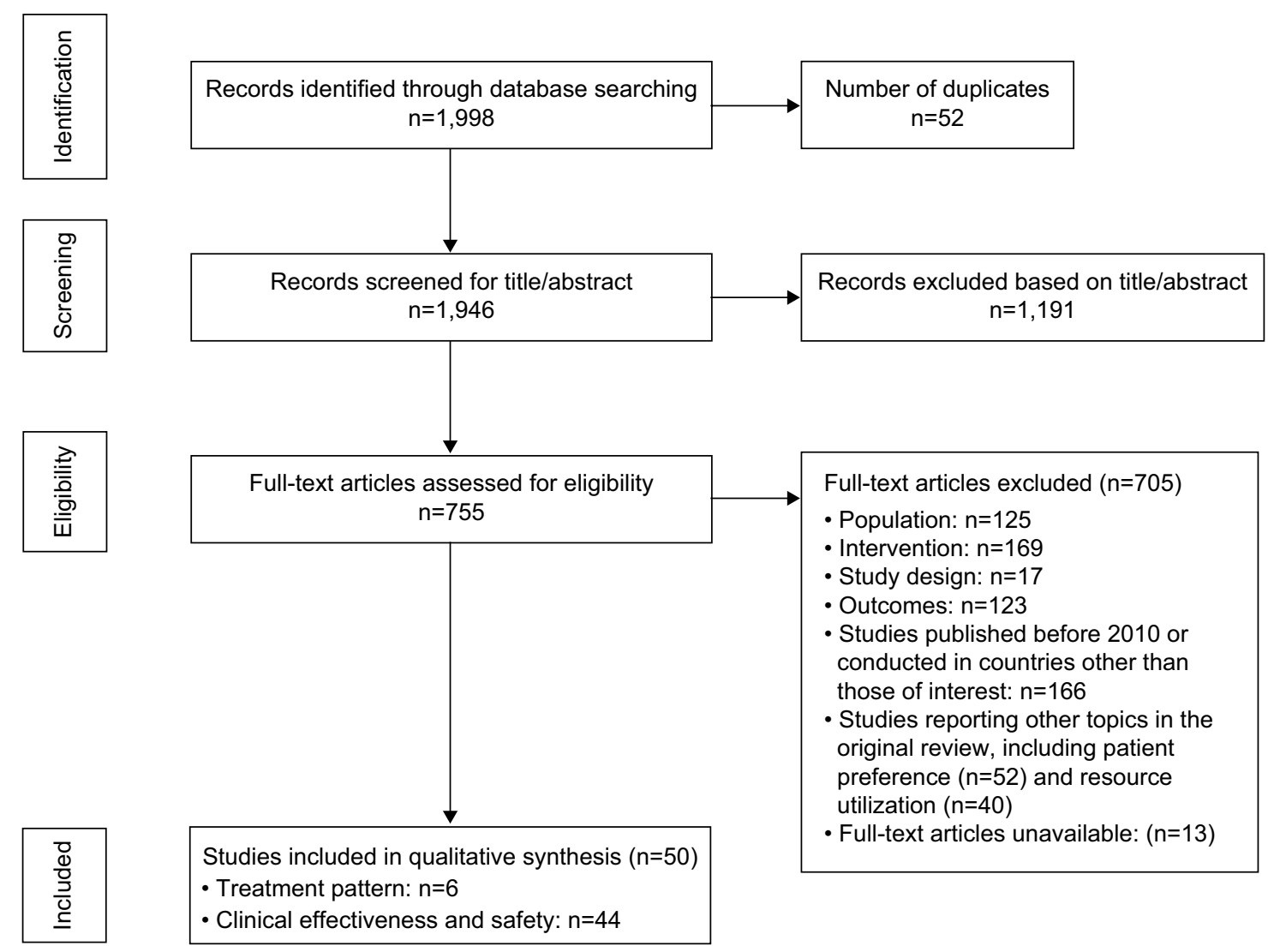

Figure I Systematic literature review of the treatment pattern and clinical effectiveness/safety of Crohn's disease: PRISMA flow chart. Abbreviation: PRISMA, Preferred Reporting Items for Systematic Reviews and Meta-Analyses.

This yielded 50 articles that were eligible for having their findings extracted and reported. Of these 50 publications, six studies reported the treatment pattern in realworld settings; 44 studies reported clinical effectiveness and safety of pharmaceutical therapies of CD in real-world clinical practice.

\section{Treatment pattern in real-world settings}

Patients with CD can be treated with dietary and lifestyle management, pharmaceutical, surgical, and other additional (eg, nutritional) interventions. In this literature review, the scope was limited to the use of pharmaceutical interventions in real-world settings only.

Six articles of interest were included for data extraction. ${ }^{14-19}$ Among these six studies, there are two crosssectional studies and four longitudinal studies (including two retrospective studies and two prospective studies). A summary of the study design, reported patient characteristics, and outcomes of each of the included publications is provided in Table 2.

Taken together, these six publications seem to paint a homogenous picture of treatment patterns in the European countries. The most commonly prescribed classes of therapy are 5-ASA, corticosteroids, and immunomodulators.
Increasing immunomodulator prescription and decreasing surgery rates and prescription of 5-ASA and corticosteroids have been reported in both the UK and Denmark. ${ }^{14,17}$ Moreover, the use of biological compounds has markedly increased during the initial year of treatment in both Eastern and Western Europe in the past decade. ${ }^{18}$ The following section reports how each category of pharmaceutical therapies is utilized in the real-life setting.

\section{5-ASA}

The usage of 5-ASA is reported in three publications. ${ }^{15,17,18}$ The percentage of patients using 5-ASA lies between $14 \%$ and $46.6 \%{ }^{15,17,18}$ The higher end of this range $(46.6 \%)$ was reported by Bokemeyer et al in Germany in $2006 .{ }^{18}$ Although without further specification of $\mathrm{CD}$ patient population regarding disease severity/activity, this finding is comparable to what was reported for the 1995-2002 cohort in a longitudinal study (1979-2011) conducted by Rungoe et al. ${ }^{17}$ In that cohort, the cumulative probability of 5-ASA use was reported to be $50.2 \%$ and $55.3 \%$ of CD patients upon 5 and 15 years since diagnosis, respectively. ${ }^{17}$ It should be noted that these probabilities are more than halved in the subsequent 2003-2011 cohort, showing a substantial decrease in the use of 5-ASA among CD patients in recent years. ${ }^{17}$ 
Table 2 Summary of studies regarding treatment pattern in CD management

\begin{tabular}{|c|c|c|c|c|c|c|c|}
\hline \multirow[t]{3}{*}{ Study } & \multirow[t]{3}{*}{ Country } & \multirow{3}{*}{$\begin{array}{l}\text { Study } \\
\text { year }\end{array}$} & \multicolumn{5}{|c|}{ Treatment pattern } \\
\hline & & & Corticosteroid & 5-ASA & $\begin{array}{l}\text { Biological } \\
\text { therapy }\end{array}$ & Immunomodulators & Other therapies \\
\hline & & & \% (drug) & $\%$ (drug) & \% (drug) & \% (drug) & \% (therapy) \\
\hline $\begin{array}{l}\text { Bokemeyer } \\
\text { et al }{ }^{18}\end{array}$ & Germany & 2006 & $\begin{array}{l}\text { Corticosteroids: } \\
\text { All patients: } 22.9 \% \\
\text { CDAI <I50: } 14.6 \% \\
\text { CDAI } \geq I 50: 32.9 \% \\
\text { Budesonide: } \\
\text { All patients: } 22.9 \% \\
\text { CDAI <I50: } 20.0 \% \\
\text { CDAI } \geq I 50: 26.4 \%\end{array}$ & $\begin{array}{l}\text { All patients: } 46.6 \% \\
\text { CDAI <I50: } 45.0 \% \\
\text { CDAI } \geq \text { I50: } 48.5 \%\end{array}$ & $\begin{array}{l}\text { Infliximab: } \\
\text { All patients: } 8.2 \% \\
\text { CDAI <150: } 6.1 \% \\
\text { CDAI } \geq 150: 10.8 \%\end{array}$ & $\begin{array}{l}\text { All patients: } 47.2 \% \\
\text { CDAI <I50: } 50.0 \% \\
\text { CDAI } \geq \text { I50: } 43.7 \%\end{array}$ & $\begin{array}{l}\text { Topical } \\
\text { medication: } \\
\text { All patients: } 4.1 \% \\
\text { CDAI <I50: } 3.2 \% \\
\text { CDAI } \geq 150: 5.2 \%\end{array}$ \\
\hline $\begin{array}{l}\text { Burisch } \\
\text { et al }{ }^{15}\end{array}$ & $\begin{array}{l}\text { Western } \\
\text { Europe }\end{array}$ & 2010 & $\begin{array}{l}\text { Initial: 35\% } \\
\text { Follow-up: 19\% }\end{array}$ & $\begin{array}{l}\text { Initial: 19\% } \\
\text { Follow-up: I4\% }\end{array}$ & $\begin{array}{l}\text { Infliximab or } \\
\text { adalimumab: } \\
\text { Initial: } 6 \% \\
\text { Follow-up: } 18 \%\end{array}$ & $\begin{array}{l}\text { Various IMs: } \\
\text { Initial: } 23 \% \\
\text { Follow-up: } 29 \%\end{array}$ & $\begin{array}{l}\text { Resection: } \\
\text { Initial: } 8 \% \\
\text { Follow-up: } 16 \%\end{array}$ \\
\hline & $\begin{array}{l}\text { Eastern } \\
\text { Europe }\end{array}$ & & $\begin{array}{l}\text { Initial: } 33 \% \\
\text { Follow-up: 23\% }\end{array}$ & $\begin{array}{l}\text { Initial: } 27 \% \\
\text { Follow-up: } 28 \%\end{array}$ & $\begin{array}{l}\text { Infliximab or } \\
\text { adalimumab: } \\
\text { Initial: } 2 \% \\
\text { Follow-up: } 6 \%\end{array}$ & $\begin{array}{l}\text { Various IMs: } \\
\text { Initial: } 25 \% \\
\text { Follow-up: 31\% }\end{array}$ & $\begin{array}{l}\text { Resection: } \\
\text { Initial: } 8 \% \\
\text { Follow-up: I2\% }\end{array}$ \\
\hline $\begin{array}{l}\text { Magro } \\
\text { et } \mathrm{al}^{19}\end{array}$ & Portugal & 2005 & $\mathrm{~N} / \mathrm{A}$ & $\mathrm{N} / \mathrm{A}$ & $\begin{array}{l}\text { All patients: } 16 \% \\
\text { Patients diagnosed: } \\
\quad \leq 16 \text { yr: } 25 \% \\
\text { I7-40 yr: } 16 \% \\
>40 \text { yr: } 16 \%\end{array}$ & $\begin{array}{l}\text { All patients: } 47 \% \\
\text { Patients diagnosed: } \\
\quad \leq 16 \text { yr: } 64 \% \\
\text { I7-40 yr: } 48 \% \\
>40 \text { yr: } 39 \%\end{array}$ & $\begin{array}{l}\text { All patients: } 43 \% \\
\text { Patients diagnosed: } \\
\text { <16 yr: } 32 \% \\
\text { I7-40 yr: } 48 \% \\
>40 \text { yr: } 30 \%\end{array}$ \\
\hline & Spain & & $N / A$ & $N / A$ & $\begin{array}{l}\text { All patients: } 33 \% \\
\text { Patients diagnosed: } \\
\text { <16 yr: } 33 \% \\
\text { I7-40 yr: } 35 \% \\
>40 \text { yr: } 24 \%\end{array}$ & $\begin{array}{l}\text { All patients: } 63 \% \\
\text { Patients diagnosed: } \\
\quad \leq 16 \text { yr: } 62 \% \\
\text { I7-40 yr: } 66 \% \\
>40 \text { yr: } 53 \%\end{array}$ & $\begin{array}{l}\text { All patients: } 38 \% \\
\text { Patients diagnosed: } \\
\quad \leq 16 \text { yr: } 24 \% \\
\text { I7-40 yr: } 41 \% \\
>40 \text { yr: } 36 \%\end{array}$ \\
\hline Burisch $^{16}$ & $\begin{array}{l}\text { Western } \\
\text { Europe } \\
\text { Eastern } \\
\text { Europe }\end{array}$ & 2010 & $\begin{array}{l}\text { First } 3 \text { mo: } 55 \% \\
\text { First } 3 \text { mo: } 54 \%\end{array}$ & $\begin{array}{l}\text { Initial: 18\% } \\
\text { Follow-up: 19\% } \\
\text { Initial: } 31 \% \\
\text { Follow-up: } 27 \%\end{array}$ & $\begin{array}{l}\text { First } 3 \text { mo: } 7 \% \\
\text { First I yr: } 21 \% \\
\text { First } 3 \text { mo: } 2 \% \\
\text { First I yr: } 6 \%\end{array}$ & $\begin{array}{l}\text { First } 3 \mathrm{mo}: 2 \% \\
\text { First } 3 \mathrm{mo}: 1 \%\end{array}$ & $\begin{array}{l}\text { Resection: } \\
\text { First I yr: } 16 \% \\
\text { Resection: } \\
\text { First I yr: I2\% }\end{array}$ \\
\hline $\begin{array}{l}\text { Ramadas } \\
\text { et } \mathrm{al}^{1 / 4}\end{array}$ & UK & $1986-2003$ & $\begin{array}{l}\text { All CD patients: } \\
\text { First } 3 \text { mo: } 63 \% \\
\text { First } 5 \text { yr: } 74 \% \\
\text { Long term: } 29 \% \\
\text { Group diagnosed } \\
\text { |986-199|: } \\
\text { First } 3 \text { mo: } 65 \% \\
\text { First } 5 \text { yr: } 75 \% \\
\text { Long term: } 44 \% \\
\text { Group diagnosed } \\
\text { I992-1997: } \\
\text { First } 3 \text { mo: } 62 \% \\
\text { First } 5 \text { yr: } 71 \% \\
\text { Long term: } 31 \% \\
\text { Group diagnosed } \\
\text { |998-2003: } \\
\text { First } 3 \text { mo: } 61 \% \\
\text { First } 5 \text { yr: } 76 \% \\
\text { Long term: } 19 \%\end{array}$ & $\mathrm{~N} / \mathrm{A}$ & N/A & $\begin{array}{l}\text { Thiopurine: } \\
\text { All CD patients: } \\
\text { First I yr: 14\% } \\
\text { First } 5 \text { yr: } 29 \% \\
\text { Group diagnosed } \\
\text { 1986-1991: } \\
\text { First } 3 \text { mo: } 3 \% \\
\text { First } 5 \text { yr: } 11 \% \\
\text { Group diagnosed } \\
\text { 1992-1997: } \\
\text { First } 3 \text { mo: } 12 \% \\
\text { First } 5 \text { yr: } 28 \% \\
\text { Group diagnosed } \\
\text { I998-2003: } \\
\text { First } 3 \text { mo: } 25 \% \\
\text { First } 5 \text { yr: } 45 \%\end{array}$ & $\begin{array}{l}\text { Intestinal surgery: } \\
43 \% \\
\text { Other surgery: } \\
5 \%\end{array}$ \\
\hline
\end{tabular}


Table 2 (Continued)

\begin{tabular}{|c|c|c|c|c|c|c|c|}
\hline \multirow[t]{3}{*}{ Study } & \multirow[t]{3}{*}{ Country } & \multirow{3}{*}{$\begin{array}{l}\text { Study } \\
\text { year }\end{array}$} & \multicolumn{5}{|c|}{ Treatment pattern } \\
\hline & & & Corticosteroid & 5-ASA & $\begin{array}{l}\text { Biological } \\
\text { therapy }\end{array}$ & Immunomodulators & Other therapies \\
\hline & & & $\%$ (drug) & $\%$ (drug) & $\%$ (drug) & $\%$ (drug) & \% (therapy) \\
\hline \multirow{15}{*}{$\begin{array}{l}\text { Rungoe } \\
\text { et } \mathrm{al}^{17, \mathrm{a}}\end{array}$} & Denmark & |979-20| | & Cohort III & Cohort III & TNF- $\alpha$ blockers: & Azathioprine: & First major \\
\hline & & & (1995-2002): & (1995-2002): & Cohort III & Cohort III & surgery: \\
\hline & & & First I yr: 26.5\% T; & First I yr: $50.2 \%$ & (1995-2002): & (1995-2002): & Cohort I: 53.8\% \\
\hline & & & $49.9 \% \bigcirc$ & First 5 yr: 54.4\% & First I yr: $0.0 \%$ & First I yr: $14.7 \%$ & Cohort II: 49.7\% \\
\hline & & & First 5 yr: $25.6 \% \mathrm{~T}$; & First 9 yr: $55.3 \%$ & First 5 yr: I.2\% & First 5 yr: $26.5 \%$ & Cohort III: 3I.4\% \\
\hline & & & $47.7 \% \mathrm{O}$ & & First 9 yr: $4.4 \%$ & First 9 yr: 30.3\% & Cohort IV: I7.5\% \\
\hline & & & First 9 yr: 28.8\% T; & & & & \\
\hline & & & $53.7 \% \mathrm{O}$ & & & & \\
\hline & & & Cohort IV & Cohort IV & Cohort IV & Cohort IV & \\
\hline & & & (2003-20II): & (2003-20II): & (2003-20II): & (2003-20II): & \\
\hline & & & First I yr: II.I\% T; & First I yr: $18.4 \%$ & First I yr: $8.2 \%$ & First I yr: $23.8 \%$ & \\
\hline & & & $24.0 \% \bigcirc$ & First 5 yr: 20.7\% & First 5 yr: $14.1 \%$ & First 5 yr: 30.3\% & \\
\hline & & & $\begin{array}{l}\text { First } 5 \text { yr: } 22.1 \% \mathrm{~T} \text {; } \\
39.8 \% \mathrm{O}\end{array}$ & First 9 yr: $21.0 \%$ & First 9 yr: $15.1 \%$ & First 9 yr: $31.0 \%$ & \\
\hline & & & First 9 yr: $22.7 \%$ T; & & & & \\
\hline & & & $41.1 \% O$ & & & & \\
\hline
\end{tabular}

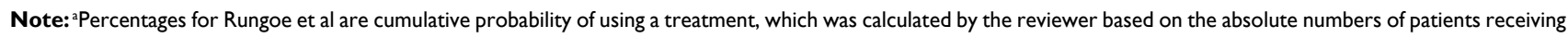
the respective therapies and the total number of patients per cohort.

Abbreviations: 5-ASA, 5-aminosalicylic acid; CD, Crohn's disease; CDAl, Crohn's Disease Activity Index; IMs, immunomodulators; mo, month(s); N/A, not available; O, oral administration; T, topical administration; TNF- $\alpha$, tumor necrosis factor- $\alpha$; yr, year(s).

\section{Corticosteroids}

How corticosteroids are used to treat $\mathrm{CD}$ is reported in five publications. ${ }^{14-18}$ The percentage of CD patients treated with corticosteroids ranges between $14.6 \%$ (based on a study including CD patients in remission (Crohn's Disease Activity Index $[\mathrm{CDAI}]<150)^{18}$ and $74 \%$ (based on a study investigating the treatment of CD patients with a 5-year follow-up period). ${ }^{14}$ In the same study, Bokemeyer et al reported a higher proportion of corticosteroids use $(32.9 \%)$ in patients with active disease (defined by CDAI $>150$ points). ${ }^{18}$ However, it is difficult to conclude that disease severity is the reason for the large variance of corticosteroid uptake reported across the studies based on the available evidence.

Some mixed findings are reported regarding the time point when corticosteroid is used since diagnosis. In a cohort study, Burisch et al found that the percentage of patients receiving corticosteroids is considerably lower in the long-term treatment of $\mathrm{CD}$, as compared to the first months of initial treatment. ${ }^{15}$ However, in a population-based historical cohort study, Ramadas et al reported that the percentage of patients receiving corticosteroids peaks in the 5-year follow-up period (rather than in the first 3 months, ie, as initial treatment) for all historical cohorts, before the percentages decline in the long term. ${ }^{14}$
Two longitudinal cohort studies that investigated the change of prescription pattern of corticosteroid over time suggested a mixed picture. ${ }^{14,17}$ In a retrospective study covering the time period from 1979 to 2011, a steady and slight upward trend was identified regarding the percentage of patients treated with corticosteroids in recent years in Denmark. ${ }^{17}$ This finding is contradictory to the result reported by Ramadas et al, who reported a statistically lower corticosteroids use (within 5 years of diagnosis) in the cohort of 1998-2003 (19\%), compared to the cohort of $1986-1991(44 \%, P=0.001)$, based on a UK population-based study. ${ }^{14}$ The different results between the two studies may be partially explained by different study designs, for example, the shorter study time and cohort duration of Ramadas et al in comparison with Rungoe et al (17 vs 32 years and 5 vs 7 years, respectively) and potential different treatment patterns in different countries. ${ }^{14,17}$

Besides the use of oral corticosteroid use, Rungoe et al also juxtapose figures about the use of topical corticosteroid. The data clearly indicate that the percentage of oral corticosteroid treatment almost doubled that of topical treatment for any cohorts or follow-up periods. The usage of topical steroid has markedly declined from the 1995-2002 cohort (cumulative probability $31 \%$ ) to the 2003-2011 cohort (cumulative probability $24 \%)(P<0.001) .{ }^{17}$ 
In most of the studies, the drug name of corticosteroid was not specified except a study by Bokemeyer et al. ${ }^{18}$ In that study, it was reported that budesonide was used among $22.9 \%$ of CD patients in Germany. ${ }^{18}$ This percentage was comparable to the percentage of $\mathrm{CD}$ patients with either active disease or disease remission ( $26.4 \%$ and $20.0 \%$, respectively) in the study. ${ }^{18}$ However, the study provided no direct evidence that budesonide was used mainly by $\mathrm{CD}$ patients with active disease or in remission.

\section{Immunomodulators}

All six included publications reported the uptake of immunomodulators. ${ }^{14-19}$ The use of immunomodulator in treating $\mathrm{CD}$ varies across different treatment timing and different countries. In a prospective study with $12 \pm 3$ months follow-up time, Burisch et al reported that in Europe, $1 \%-2 \%$ of CD patients used immunomodulators during the first 3 months after diagnosis. ${ }^{16}$ Approximately $14 \%-25 \%$ of CD patients had immunomodulators as an initial treatment (during the first 1 year after diagnosis) and $29 \%-31 \%$ of CD patients had it as follow-up treatment. ${ }^{14,15}$ Some variance of the use of immunomodulators was noticed across countries. For example, the percentage of CD patients using this therapy was reported to be $63 \%$ and $47 \%$ in Spain and Portugal, respectively. ${ }^{19}$ In Denmark and the rest of Europe, immunomodulators were used among $<31 \% \mathrm{CD}$ patients. ${ }^{17}$

Two longitudinal studies with long follow-up period: Ramadas et al (17 years follow-up) ${ }^{14}$ and Rungoe et al (16 years follow-up) ${ }^{17}$ suggested a trend of increasing use of immunomodulator among CD patients over the past 2 decades, both as an early therapy during the first year and overall therapy regardless of time to diagnosis. In the study conducted by Ramadas et al, three population-based cohorts (Group A: 1986-1991; Group B: 1992-1997; Group C: 1998-2003) of CD patients from Cardiff (UK) were investigated. ${ }^{14}$ It was found that between 1986 and 2003, there was a significant increase in the early and overall use of thiopurine (ie, AZA and 6-MP). Early use (within 1 year of diagnosis) of thiopurines increased from 3\% in Group A to $12 \%$ in Group B and $25 \%$ in Group $\mathrm{C}(P<0.001)$. Five years after diagnosis, thiopurine had been used in $11 \%$ of Group A, $28 \%$ in Group B, and $45 \%$ in Group C $(P<0.001)$. Similar trend was observed by Rungoe et al in Denmark, especially for the first year after diagnosis. ${ }^{17}$ Comparing the use of AZA between the 1995-2002 cohort and the 2003-2011 cohort, the cumulative probability of CD patients with AZA therapy were $15 \%$ versus $25 \%(P<0.001) ; 28 \%$ versus $36 \%$
$(P=0.18)$; and $32 \%$ versus $39 \%(P=0.70)$ among these two cohorts for the first year, the first 5 years and the first 9 years after diagnosis, respectively. ${ }^{17}$

\section{Biological therapy}

With the exception of Ramadas et al, ${ }^{14}$ all included publications provided data on the usage of biological compounds in CD treatment. The type of biological compounds under investigation varied between publications and was not always reported.

Among the publications, the highest percentage of CD patients with biological treatment was reported as $33 \%$ by Magro et al in a study among hospitalized CD patients in Galicia, Spain. ${ }^{19}$ The same study reported that $35 \%$ of the patients with their age at diagnosis between 17 and 40 years received biological therapy (being classified as severe refractory disease in the study). ${ }^{19}$ By comparison, all four other articles reported a much lower percentage of between $8 \%$ and $25 \%$ of CD patients receiving biological therapy. ${ }^{15-18}$

From a longitudinal point of view, there seems to be an increase in the uptake of biological therapy. In a Danish retrospective study conducted by Rungoe et al, it was found that the highest percentage of biologic therapy use among CD patients was $15.1 \%$ in the 2003-2011 cohort, which was significantly higher compared with $4.4 \%$ which was reported in the 1995-2002 cohort. $^{17}$

\section{Additional therapies}

Of all included publications, only the study by Bokemeyer et al reports the use of additional, nonsurgical therapy (ie, rectal administration of 5-ASA, budesonide, or hydrocortisone) in Germany. ${ }^{18}$ It was reported that $4.1 \%$ of all CD patients received topical medication. This percentage was reported to be $3.2 \%$ and $5.2 \%$ for patients with inactive (CDAI score of $<150)$ and active disease (CDAI $\geq 150)$, respectively.

\section{Clinical effectiveness and safety of pharmaceutical treatments in real-world clinical practice}

In total, 44 publications were included in this review regarding the clinical effectiveness and safety of pharmaceutical treatments of $\mathrm{CD}$ in real-world settings. Majority of the studies were longitudinal studies $(n=43,98 \%)$. A large part of the 43 longitudinal studies were retrospective studies $(n=33)$; there are ten prospective studies. Twenty-five studies had a follow-up time of $>12$ months; five studies were short-term 
ones with $\leq 12$ months follow-up time; the rest of the studies failed to report their follow-up time.

Majority of the studies $(n=23,52.3 \%)$ were performed in an outpatient setting. Fourteen studies (31.8\%) included both in- and outpatient data. For the remaining studies (15.9\%), no information on treatment setting was specified.

It is important to note that there are substantial differences regarding how clinical effectiveness is measured (ie, how clinical remission/response is defined) across the observational studies. There are two general approaches adopted by the studies to define clinical remission/response. The first approach is to define clinical response according to symptoms control in a steroid-free setting, measured by either some standard tools (ie, CDAI [remission defined as CDAI <150], or Harvey-Bradshaw Index [HBI; remission defined as HBI <4]), judgment of a physician, or need for surgery. Another approach is to define clinical response with respect to the changes in some inflammatory indexes (also in a steroid-free setting), for example, erythrocyte sedimentation rate or $\mathrm{C}$-reactive protein.

Therefore, although the results from these studies can be summarized, they cannot be compared with one another directly because of the variance among the measurements of the studies.

\section{Infliximab}

\section{Clinical effectiveness}

Dose escalation of infliximab was allowed from $5 \mathrm{mg} / \mathrm{kg}$ (according to the label) to $10 \mathrm{mg} / \mathrm{kg}$ in four studies. ${ }^{20-23}$ Taxonera et $\mathrm{al}^{24}$ reported a rate of dose intensification per patient-month of $1.4 \%$ for $\mathrm{CD}$ patients. ${ }^{24}$ The median time from baseline to intensification was 10.6 months. ${ }^{24} \mathrm{~A}$ similar rate of dose escalation was reported as $2.4 \%$ in 12 months and $5.0 \%$ in 24 months after infliximab treatment was initiated. ${ }^{22}$ When infliximab was reintroduced after a previous treatment (reasons of discontinuation unknown), 45\% of patients received an intensified dosing schedule $(>5 \mathrm{mg} / \mathrm{kg})$. In the rest of the studies, infliximab was used according to the label $(5 \mathrm{mg} / \mathrm{kg})$ or dosage was not reported. Clinical effectiveness of infliximab was reported using remission rate, response rate, recurrence rate, and need for surgery.

The percentage of patients reaching clinical remission at the end of the study was reported in four studies. ${ }^{20,21,23,25} \mathrm{~A}$ difference exists in the definition of clinical remission (eg, measured by HBI index or C-reactive protein values) and variance in patient groups in terms of age and disease activity. Remission rates at the end of the study were reported by three studies as $31 \%$ (median follow-up time $\geq 18$ months), ${ }^{20}$
$57 \%$ (median follow-up time 22 months), ${ }^{23}$ and $74 \%$ (follow-up time not reported). ${ }^{21}$ It is important to note that the two studies ${ }^{21,23}$ reporting relatively high remission rates included patients treated with an escalated infliximab dose of $10 \mathrm{mg} / \mathrm{kg}$. One additional study conducted by Chauvin et al reported 1 - and 2-year remission rates as $56 \%$ and $36 \%$, respectively. ${ }^{25}$

In a retrospective hospital record analysis conducted by Antakia et al, $25 \%$ and $42 \%$ patients with complex CD (combined with fistula) achieved complete and partial response (defined by fistula drainage assessment endpoints), respectively, under infliximab therapy in $\mathrm{UK} .{ }^{26}$ Also from a hospital record analysis but conducted in Portugal, Magro et al reported a sustained response (defined as response sustained for at least 1 year of treatment), short-term response (defined as response with $<1$ year of treatment), and response rate with therapeutic adjustment of $10.3 \%, 67 \%$, and $22.7 \%$, respectively. ${ }^{27}$

It was not uncommon that CD patients still experience recurrence under infliximab treatment. In a retrospective study with 12 years follow-up, Chauvin reported a recurrence rate of $68 \%$ among $\mathrm{CD}$ patients using infliximab treatment as maintenance therapy. ${ }^{25} \mathrm{~A}$ small-scale $(\mathrm{N}=12)$ prospective cohort study conducted by Sorrentino et al (median followup time: 3 years) found that infliximab did not show clinical benefit of preventing recurrence once patients stopped using it: among the 12 postsurgery $C D$ patients using infliximab as maintenance therapy, ten $(83 \%)$ reported recurrence after 3 years of infliximab treatment followed by 16 weeks of no treatment. $^{28}$

As surgical interventions can be an option for severe CD patients, the need for surgery is also sometimes used as an indicator of the clinical effectiveness of a therapy. The rate of need for surgery varied a lot between the two studies that reported this outcome. In the retrospective study conducted in Portugal (median follow-up time 21 months), Magro et al reported a $1 \%$ surgery rate among patients receiving infliximab as maintenance therapy $(\mathrm{N}=148) .{ }^{27}$ In a Dutch database analysis, Brandse et al investigated the clinical effectiveness of a sequential therapy (starting with sequential infliximab and adalimumab, both for 3 months, and followed by infliximab treatment only after adalimumab discontinuation). ${ }^{20} \mathrm{It}$ was reported that $24 \%$ of the patients underwent surgeries during the follow-up period ( $\geq 18$ months).

\section{Safety}

A wide range of adverse events has been reported for infliximab, although the occurrence is rare for most of 
them, including mortality, ${ }^{29}$ infusion reactions, ${ }^{20,23,25}$ rash, ${ }^{26}$ nausea, ${ }^{26}$ and herpes. ${ }^{23}$ Abscess is a more frequently reported as adverse event among $31 \%(\mathrm{~N}=48)$ of $\mathrm{CD}$ patients with infliximab treatment. ${ }^{29}$

\section{Adalimumab}

\section{Clinical effectiveness}

In all studies where dosage was reported, the following regimen was used: 160 and $80 \mathrm{mg}$ for induction at week 0 and 2 , respectively, followed by maintenance treatment of $40 \mathrm{mg}$ every 2 weeks. However, dose escalation of adalimumab was observed and reported by Bultman et al in over one-third of the cohort within a median follow-up time of 5 months. ${ }^{30}$ There are also a few studies that reported the impact of escalated dosage of adalimumab (ie, from $40 \mathrm{mg}$ every 2 weeks to $80 \mathrm{mg}$ every 2 weeks as maintenance dosage) on its clinical effectiveness. ${ }^{31-33}$ It was concluded that approximately onethird of the patients needed a dose escalation to maintain clinical response within 5-7 months.

As studies investigating the clinical effectiveness of infliximab in treating $C D$ patients, clinical effectiveness of adalimumab was reported using measures such as remission rate, response rate, recurrence rate, and need for surgery. In all studies, CD remission is defined according to symptoms relief in a steroid-free environment, either assessed by global physician's assessment or CDAI or HBI index.

With a definition of CDAI $<150$ or $\mathrm{HBI}<4$ as remission for CD patients, Russo et al reported a remission rate of $57 \%$ $(\mathrm{N}=61)$ among patients who were exposed to maintenance adalimumab therapy with an average follow-up of 8 months in the UK and Ireland. ${ }^{34}$ Similar rate was reported by Amiot et al, though with a very small sample size $(\mathrm{N}=5)$ and unclear definition of CD remission. ${ }^{29}$

The reported 12 months remission rates varied widely (from $20 \%{ }^{35}$ to $86 \%{ }^{36}$ ) across the three other studies that reported the rates. ${ }^{32,35,36}$ Average length of remission was reported by only one study, which found an average length of remission of 7.9 months (range 1-35 months). ${ }^{34}$

In a retrospective study with 36 weeks follow-up period, Fortea-Ormaechea et al reported a complete response rate (defined as disappearance of symptoms according to the clinical evaluation of the supervising physician and normalization of all inflammation parameters without the need of glucocorticoids therapy) of $41.5 \%$ and a partial response rate (defined as a significant improvement in symptoms and inflammation parameters, but without full resolution) of $35.8 \%$ at the end of the follow-up. ${ }^{37} \mathrm{CD}$ patients who do not respond to adalimumab seem to have the possibility of responding with higher dose of this drug. In a study investigating the outcome of dose escalation and de-escalation of adalimumab in treating CD patients, Baert et al concluded that adalimumab dose escalation reinduced clinical response for at least 6 months in $67 \%$ of patients. ${ }^{31}$

Similar to other treatments, adalimumab does not cure CD. The patients who achieved clinical remission/response are still at risk of recurrence. Chaparro et al reported a loss of response (LOR) in $18 \%$ per patient-year of follow-up. ${ }^{36}$

The need for surgery among CD patients under adalimumab treatment was investigated by Peters et al. In a retrospective analysis of the medical records of all CD patients in the Dutch province of North-Holland (median follow-up time $=2$ years), Peter et al reported that 9.3 abdominal surgical interventions had been performed per 100 patient-years by the end of follow-up. ${ }^{35}$

\section{Safety}

A diverse picture was revealed regarding the safety of adalimumab in treating $\mathrm{CD}$ patients. In a study (36 weeks followup time) conducted by Fortea-Ormaechea et al $(\mathrm{N}=174)$, $18.4 \%$ of the patients experienced adverse events. ${ }^{37}$ The most frequently reported adverse event was intra-abdominal abscess and rash: reported in five (15.6\%) and four (12.5\%) patients experienced adverse events, respectively. Other adverse events that were reported in less than three patients included injection pain, aggravated psoriasis, upper respiratory tract infections, anaphylactoid reaction, muscle pain, headache, varicella, pneumonia, dental infection, herpes zoster, diarrhea, and cough. ${ }^{37}$ Baert et al reported similar findings in a study with longer follow-up time (median follow-up: 14 months) and larger sample size $(\mathrm{N}=720){ }^{31}$ Severe adverse events that required hospitalization were reported to be rare $(n<3)$ and included death; gastroenteritis; clostridium infection; acute viral syndrome with fever; herpes zoster/zona; pneumonia; exacerbation of CD such as flare-up, small bowel obstruction, perforation, abscess, actively drainage fistulae, elective surgery; pulmonary embolism; ulcerative skin lesions, renal cell carcinoma, multiple sclerosis, and stroke. ${ }^{31}$ Other rare adverse events included hair loss and malignancies. ${ }^{35}$

\section{Thiopurines:AZA or 6-MP}

AZA was the treatment of interest in three studies. ${ }^{38-40}$ Five studies investigated thiopurines such as AZA or 6-MP as a treatment group, with results not distinguishable by drugs. Two studies investigated these drugs in combination with anti-TNF- $\alpha$ drugs. ${ }^{41,42}$ 


\section{Clinical effectiveness}

Relapse rate among thiopurine responders was reported by two studies. ${ }^{38,43}$ In a retrospective database analysis based on MICISTA database in France with a median follow-up time of 12.6 years, CD patients who responded to AZA (defined as achieving clinical remission during the fourth trimester after the introduction of AZA and off steroids) were followed-up for relapses. ${ }^{38}$ Cumulative relapse rates of 5 and 10 years after inclusion were reported to be $45 \%$ and $62 \%$, respectively. In another retrospective study based on hospital records among CD patients who had continuous thiopurine use $\geq 35$ months, Kennedy et al reported that $23 \%$ of patients had a moderateto-severe relapse within 12 months of thiopurine withdrawal $(\mathrm{N}=129) .{ }^{43}$

For CD patients undergoing thiopurine therapy, the need for surgery was reported by a few papers with substantial difference in their results. Camus et al found that among responders to AZA, the need for surgery was $2.3 \%$ per patient-year. ${ }^{38}$ In another study conducted by Lee et al with a mixed CD population of AZA tolerance and intolerance groups ( $26 \%$ intolerance), the need for surgery was reported to be $48 \%$ of the whole sample. ${ }^{39}$

\section{Safety}

Mortality among patients undergoing AZA treatment was reported in several studies. In the study conducted by Camus et al with 12.6 years median follow-up time, eleven (5\%) deaths were reported, including eight cancer-related deaths. ${ }^{38}$ Costantino reported one death among CD patients receiving either AZA or 6-MP $(\mathrm{N}=157)$, probably due to hemophagocytic lymphohistiocytic syndrome complicated by liver failure. ${ }^{44}$

\section{Discussion}

Immunomodulators and biological therapies have been developed as options for CD patients beyond 5-ASA and corticosteroids. There is evidence to support the early use of conventional immunomodulators and biological therapies in the treatment of moderate to severe $\mathrm{CD}$, that is, for $\mathrm{CD}$ patients who do not respond to and/or tolerate 5-ASA or corticosteroids or for those who are otherwise steroiddependent. ${ }^{45,46}$ Our findings regarding the treatment pattern confirmed a shift from traditional treatment using 5-ASA and corticosteroids to immunomodulators and biologics in the European countries.

This review identified the following unmet medical needs in managing $\mathrm{CD}$ patients.
- 5-ASA and corticosteroids remain the most widely used treatments for $\mathrm{CD}$ patients in the majority of the European countries, though whether clinical benefits outweigh side effects has been a topic of debate for decades. ${ }^{10,47}$ Immunomodulators and biologics, with better clinical effectiveness, are still second-line treatments for patients who either do not respond to or tolerate the first-line therapies according to the ECCO clinical guideline. ${ }^{5}$ However, we observed an increasing uptake of these drugs in recent years, ${ }^{16}$ which suggests that there is an unmet medical needs in the management of CD with the most widely used therapies (ie, 5-ASA and corticosteroids).

- Around half of CD patients responded to immunomodulators and biologics within 1 or 2 years after the treatment was initiated. However, this also means that the other half of patients did not achieve a satisfactory response to these therapies. Moreover, even among those who responded to the therapies, recurrence and relapse were not unusual. Surgeries were still required in some patients. For example, Chauvin et al reported a recurrence rate of $68 \%$ among CD patients with infliximab treatment in a 12-years retrospective study. 25

- With a mechanism of (targeted) modulating immunemediated inflammation, immunomodulators and biologics do not cure the disease and have to be used as maintenance treatments. A substantial proportion of CD patients are likely to experience disease relapse/ recurrence if they stop using these therapies. Even while using immunomodulators as a maintenance treatment, there was a high chance of LOR in the long term due to immunogenicity. ${ }^{48}$ Although there is no clear definition of LOR, some papers defined LOR in practical ways such as need for dose escalation over time, and sometimes also discontinuation of treatments. ${ }^{48}$ Dose escalation falls out of the scope of this literature review. However, dose escalation of adalimumab (ie, from $40 \mathrm{mg}$ every 2 weeks to $80 \mathrm{mg}$ every 2 weeks as maintenance dosage) was observed and reported by a few studies, which suggest a LOR with adalimumab. ${ }^{31-33}$ It was also reported that approximately one-third of the patients needed a dose escalation of adalimumab to maintain clinical response within 5-7 months. ${ }^{31-33}$ Indirect evidence of LOR with infliximab was also reported by Magro et al that the shortterm response rate $(67 \%)$ was much higher compared with a sustained response rate $(10.3 \%)$ defined as response sustained for at least 1 year of treatment). ${ }^{27}$ 
More options in the pharmaceutical management of CD are needed to meet the unmet needs of patients. This review is the first systematic literature review to summarize the treatment pattern of pharmaceutical therapies in CD management and the clinical effectiveness and safety of the major pharmaceutical therapies in the real-world setting. There are three potential limitations of this review.

First, this review has a geographic scope of European countries, including the UK, Germany, France, Spain, Italy, Sweden, Norway, Denmark, Finland, Belgium, the Netherlands, Luxemburg, and Portugal. There lies variance across the health care system in different countries, which leads to a potential accessibility issue of certain drugs (especially expensive drugs). Therefore, the findings, especially regarding treatment patterns, need to be interpreted with caution when they are to be generalized to other countries.

Second, a time limit of the past 5 years has been applied during the selection phase. Therefore, this review is not powered to draw a solid conclusion regarding a change of treatment pattern in $\mathrm{CD}$ management. The current conclusion regarding treatment trend was given on the basis of several longitudinal studies with long follow-up time.

Last, the studies included in this literature review have a mixed study design of cross-sectional study, retrospective study, and prospective study. This variance of the study design might have impact on the result and the direction of the impact is unclear. Therefore, the combined result of this review should only be taken as a qualitative summary of the finding.

Some knowledge gaps, which deserve further research, are revealed by this systematic literature review.

- Dose escalation of infliximab, adalimumab, and thiopurines has been observed and/or allowed in several studies, suggesting that it is an existing clinical practice to use higher-than-label dose in the management of CD patients. There is a lack of large-scale studies with long follow-up time to explore the impact of escalated dose of immunomodulators and biologics in terms of clinical effectiveness and safety in CD treatment.

- There is a lack of knowledge regarding the length of remission maintenance with immunomodulatory and biologics therapies. Although most of the studies identified by this review reported remission rates with a follow-up time of $>18$ months, there is no direct evidence showing how sustainable the clinical effectiveness of these therapies are.
- Limited evidence has been identified from this review to provide an overview of medications used for $\mathrm{CD}$ patients of different disease severities. This is an important area that deserves future investigation because the choice of medication in the treatment of CD highly depends on the severity of the disease.

- Both immunomodulators and biologics should be used as maintenance therapies to prevent recurrence of $\mathrm{CD}$. However, most of the studies identified in this review are focused on the clinical effectiveness. Large-scale long-term safety studies in the real-world settings are needed for these therapies.

- There is a need for research studies to investigate the optimal mode of administration (systemic use vs local injection) in the treatment of perianal fistulae $\mathrm{CD}$ patients.

\section{Conclusion}

This systematic literature review aimed to give an overview of the treatment pattern of pharmaceutical therapies in CD management and clinical effectiveness and safety of the therapies in the real-world settings of the European countries. Although there are limited number of studies that investigated the use of pharmaceutical therapies in $\mathrm{CD}$, these studies suggested a similar pattern in Europe. 5-ASA and corticosteroids have been widely used among CD patients, although there has been a trend of decreasing prescription in recent years. No studies investigating the clinical effectiveness and safety of 5-ASA and corticosteroids in the real-world setting has been identified, showing a lack of interest of researchers and/ or physicians in this topic.

Immunomodulators and biological therapies appear to be promising treatment options in CD management and have been increasingly used in Europe in recent years, especially as long-term maintenance treatments. ${ }^{28}$ Due to the variance in how clinical effectiveness is measured across the studies, the results are not directly comparable. Nevertheless, clinical effectiveness is mainly measured by symptom-based measurements, for example, remission rate, response rate, CDAI, HBI. Based on the results reported by the identified studies, infliximab, adalimumab, and thiopurines are likely to achieve a remission rate of $\sim 50 \%$ as maintenance therapies. Dose escalation was observed among approximately one-third and half of the $\mathrm{CD}$ patients receiving infliximab and adalimumab treatments, respectively, within 5-7 months. However, a substantial recurrence/relapse rate (18\% per patient-year ${ }^{36}$ and cumulatively up to $83 \%{ }^{28}$ ) was also reported among patients who were under immunomodulator or biological treatments, and especially among those who discontinued the treatments. 
Few major safety issues have been reported regarding these immunomodulators and biological therapies besides those that are widely recognized with these agents.

\section{Acknowledgments}

We would like to thank Bas van Dijk (employed by Pharmerit) for editing the manuscript. Search and selection and data extraction were supported by Krystallia Pantiri, Bas van Dijk, and Katharina Verleger, who are employees of Pharmerit International. This study received financial support from Janssen Pharmaceutical.

\section{Disclosure}

Weiwei Xu is employed by Pharmerit International. Filippo Lelli, Solomon Nuhoho, and Xin Ying Lee are employed by Janssen Pharmaceutical affiliates. The authors report no conflicts of interest in this work.

\section{References}

1. Geller SA, Campos FPF de. Crohn disease. Autops Case Reports. 2015;5(2):5-8.

2. Freeman HJ. Natural history and long-term clinical course of Crohn's disease. World J Gastroenterol. 2014;20(1):31-36.

3. Mayberry JF, Lobo A, Ford AC, Thomas A. NICE clinical guideline (CG152): the management of Crohn's disease in adults, children and young people. Aliment Pharmacol Ther. 2013;37(2):195-203.

4. Carpio D, Barreiro-de Acosta M, Echarri A, et al. Influence of urban/ rural and coastal/inland environment on the prevalence, phenotype, and clinical course of inflammatory bowel disease patients from northwest of Spain: a cross-sectional study. Eur J Gastroenterol Hepatol. 2015;27(9):1030-1037.

5. Dignass A, Van Assche G, Lindsay JO, et al. The second European evidence-based consensus on the diagnosis and management of Crohn's disease: current management. J Crohn's Colitis. 2010;4(1): 28-62.

6. Vuitton L, Koch S, Peyrin-Biroulet L. Janus kinase inhibition with tofacitinib: changing the face of inflammatory bowel disease treatment. Curr Drug Targets. 2013;14(12):1385-1391.

7. NICE. Vedolizumab for Treating Moderately to Severely Active Ulcerative Colitis (TA 342). Available from: https://www.nice.org.uk/guidance/TA342/chapter/2-The-technology. Accessed March 14, 2015.

8. McLean LP, Shea-Donohue T, Cross RK. Vedolizumab for the treatment of ulcerative colitis and Crohn's disease. Immunotherapy. 2012;4(9):883-898.

9. Sandborn WJ, Gasink C, Gao L-L, et al. Ustekinumab induction and maintenance therapy in refractory Crohn's disease. $N$ Engl J Med. 2012;367(16):1519-1528.

10. Kuenzig ME, Rezaie A, Seow CH, et al. Budesonide for maintenance of remission in Crohn's disease. Cochrane Database Syst Rev. 2014;8:CD002913.

11. Ford AC, Sandborn WJ, Khan KJ, Hanauer SB, Talley NJ, Moayyedi P. Efficacy of biological therapies in inflammatory bowel disease: systematic review and meta-analysis. Am J Gastroenterol. 2011;106(4):644-659.

12. Chande N, Tsoulis DJ, MacDonald JK. Azathioprine or 6-mercaptopurine for induction of remission in Crohn's disease. Cochrane Database Syst Rev. 2013;30(4):CD000545.

13. Scottisch Intercollegiate Guideline Network (SIGN). "Search filters." Available from: http://www.sign.ac.uk/methodology/filters.html. Published 2015. Accessed March 1, 2015.
14. Ramadas AV, Gunesh S, Thomas GA, Williams GT, Hawthorne AB. Natural history of Crohn's disease in a population-based cohort from Cardiff (1986-2003): a study of changes in medical treatment and surgical resection rates. Gut. 2010;59(9):1200-1206.

15. Burisch J, Pedersen N, Cukovic-Cavka S, et al. Initial disease course and treatment in an inflammatory bowel disease inception cohort in Europe: the ECCO-EpiCom cohort. Inflamm Bowel Dis. 2014;20(1):36-46.

16. Burisch J. Crohn's disease and ulcerative colitis: occurrence, course and prognosis during the first year of disease in a European population-based inception cohort. Dan Med J. 2014;61(1):B4778.

17. Rungoe C, Langholz E, Andersson M, Basit S, Nielsen NM, Wohlfahrt J, Jess T. Changes in medical treatment and surgery rates in inflammatory bowel disease: a nationwide cohort study 1979-2011. Gut. 2014;:1-10.

18. Bokemeyer B, Hardt J, Hüppe D, et al. Clinical status, psychosocial impairments, medical treatment and health care costs for patients with inflammatory bowel disease (IBD) in Germany: an online IBD registry. J Crohn's Colitis. 2013;7(5):355-368.

19. Magro F, Barreiro-de Acosta M, Lago P, et al. Clinical practice in Crohn's disease in bordering regions of two countries: different medical options, distinct surgical events. J Crohn's Colitis. 2010;4(3):301-311.

20. Brandse JF, Peters CP, Gecse KB, et al. Effects of infliximab retreatment after consecutive discontinuation of infliximab and adalimumab in refractory Crohn's disease. Inflamm Bowel Dis. 2014;20(2): 251-258.

21. Paul S, Del Tedesco E, Marotte H, et al. Therapeutic drug monitoring of infliximab and mucosal healing in inflammatory bowel disease: a prospective study. Inflamm Bowel Dis. 2013;19(12):2568-2576.

22. Lindsay JO, Chipperfield R, Giles A, Wheeler C, Orchard T; INDIGO Study Investigators. A UK retrospective observational study of clinical outcomes and healthcare resource utilisation of infliximab treatment in Crohn's disease. Aliment Pharmacol Ther. 2013;38(1):52-61.

23. Chaparro M, Martínez-Montiel P, Van Domselaar M, et al. Intensification of infliximab therapy in Crohn's disease: efficacy and safety. $J$ Crohn's Colitis. 2012;6(1):62-67.

24. Taxonera C, Olivares D, Mendoza JL, et al. Need for infliximab dose intensification in Crohn's disease and ulcerative colitis. World J Gastroenterol. 2014;20(27):9170-9177.

25. Chauvin A, Le Thuaut A, Belhassan M, et al. Infliximab as a bridge to remission maintained by antimetabolite therapy in Crohn's disease: a retrospective study. Dig Liver Dis. 2014;46(8):695-700.

26. Antakia R, Shorthouse AJ, Robinson K, Lobo AJ. Combined modality treatment for complex fistulating perianal Crohn's disease. Color Dis. 2013;15(2):210-216.

27. Magro F, Rodrigues-Pinto E, Santos-Antunes J, et al. High C-reactive protein in Crohn's disease patients predicts nonresponse to infliximab treatment. J Crohn's Colitis. 2014;8(2):129-136.

28. Sorrentino D, Paviotti A, Terrosu G, Avellini C, Geraci M, Zarifi D. Low-dose maintenance therapy with infliximab prevents postsurgical recurrence of Crohn's disease. Clin Gastroenterol Hepatol. 2010;8(7):591-599.

29. Amiot A, Setakhr V, Seksik P, et al. Long-term outcome of enterocutaneous fistula in patients with Crohn's disease treated with antiTNF therapy: a cohort study from the GETAID. Am J Gastroenterol. 2014;109(9):1443-1449.

30. Bultman E, De Haar C, Van Liere-Baron A, et al. Predictors of dose escalation of adalimumab in a prospective cohort of Crohn's disease patients. Aliment Pharmacol Ther. 2012;35(3):335-341.

31. Baert F, Glorieus E, Reenaers C, et al. Adalimumab dose escalation and dose de-escalation success rate and predictors in a large national cohort of Crohn's patients. J Crohn's Colitis. 2013;7(2):154-160.

32. Filippi J, Agrefilo D, Fontas E, Hébuterne X. Comparison of efficacy and tolerance of two maintenance regimens with adalimumab in patients with moderate to severe Crohn's disease. Gastroenterology. 2013;144 (5, Sppl 1):S433.

33. Choi GKH, Collins SDE, Greer DP, et al. Costs of adalimumab versus infliximab as first-line biological therapy for luminal Crohn's disease. J Crohn's Colitis. 2014;8(5):375-383. 
34. Russo EA, Iacucci M, Lindsay JO, et al. Survey on the use of adalimumab as maintenance therapy in Crohn's disease in England and Ireland. Eur J Gastroenterol Hepatol. 2010;22(3):334-339.

35. Peters CP, Eshuis EJ, Toxopeüs FM, et al. Adalimumab for Crohn's disease: long-term sustained benefit in a population-based cohort of 438 patients. J Crohn's Colitis. 2014;8(8):866-875.

36. Chaparro M, Panés J, García V, et al. Long-term durability of response to adalimumab in Crohn's disease. Inflamm Bowel Dis. 2012;18(4): 685-690.

37. Fortea-Ormaechea JI, González-Lama Y, Casis B, et al. Adalimumab is effective in long-term real life clinical practice in both luminal and perianal Crohn's disease. The Madrid experience. Gastroenterol Hepatol. 2011;34(7):443-448.

38. Camus M, Seksik P, Bourrier A, et al. Long-term outcome of patients with Crohn's disease who respond to azathioprine. Clin Gastroenterol Hepatol. 2013;11(4):389-394.

39. Lee LYW, Gardezi AS, Santharam V, Boyd J, Lanzon-Miller S. Effect of azathioprine intolerance on outcomes of inflammatory bowel disease: a cross-sectional study. Frontline Gastroenterol. 2013;5(1): 40-43.

40. Rao A, Tshuma NB, Goodhand JR, et al. Response to azathioprine in adults and children with inflammatory bowel disease is comparable when phenotype is controlled. Poster presented at: European Society for Paediatric Gastroenterology, Hepatology, and Nutrition Annual Meeting; 2010; Istanbul, Turkey.
41. González-Lama Y, Gomollon F, Hinojosa J, et al. Work productivity and activity impairment in Spanish Crohn's disease patients: P265. In: Advances in Inflammatory Bowel Diseases; 2012.

42. Gómez-García M, Cabello-Tapia MJ, Sánchez-Capilla AD, deTeresaGalván J, Redondo-Cerezo E. Thiopurines related malignancies in inflammatory bowel disease: local experience in Granada, Spain. World J Gastroenterol. 2013;19(30):4877-4886.

43. Kennedy NA, Kalla R, Warner B, et al. Thiopurine withdrawal during sustained clinical remission in inflammatory bowel disease: relapse and recapture rates, with predictive factors in 237 patients. Aliment Pharmacol Ther. 2014;40(11-12):1313-1323.

44. Costantino G, Furfaro F, Belvedere A, Alibrandi A, Fries W. Thiopurine treatment in inflammatory bowel disease: response predictors, safety, and withdrawal in follow-up. J Crohn's Colitis. 2012;6(5):588-596.

45. Ardizzone S, Cassinotti A, Manes G, Porro GB. Immunomodulators for all patients with inflammatory bowel disease? Therap Adv Gastroenterol. 2010;3(1):31-42.

46. Panaccione R, Ghosh S. Optimal use of biologics in the management of Crohn's disease. Therap Adv Gastroenterol. 2010;3(3):179-189.

47. Perrotta C, Pellegrino P, Moroni E, et al. Five-aminosalicylic acid: an update for the reappraisal of an old drug. Gastroenterol Res Pract. 2015;2015:456895.

48. Ben-Horin S, Chowers Y. Review article: loss of response to anti-TNF treatments in Crohn's disease. Aliment Pharmacol Ther. 2011;33(9) 987-995.
Clinical and Experimental Gastroenterology

\section{Publish your work in this journal}

Clinical and Experimental Gastroenterology is an international, peerreviewed, open access, online journal publishing original research, reports, editorials, reviews and commentaries on all aspects of gastroenterology in the clinic and laboratory. This journal is included on PubMed. The manuscript management system is completely online

\section{Dovepress}

and includes a very quick and fair peer-review system, which is all easy to use. Visit http://www.dovepress.com/testimonials.php to read real quotes from published authors. 